\title{
Theoretical ultrasonic velocities in binary liquid mixture containing aniline and anisole at different temperatures - a comparative study
}

\author{
Y. Sreedevi $i^{1, *}$, Ch. Srinivasu ${ }^{2}$, Sk. Fakruddin ${ }^{3}$, K. Narendra ${ }^{3}$, \\ B. R. Venkateswara Rao ${ }^{3}$, Y. Nirmal Rajeev ${ }^{3}$ \\ ${ }^{1}$ Research Scholar, Department of Physics, Andhra Loyola College, Vijayawada - 520008 (A.P), India. \\ ${ }^{2}$ Department of Physics, Andhra Loyola College, Vijayawada - 520008 (A.P), India \\ ${ }^{3}$ Department of Physics, V. R. Siddhartha Engineering College, Vijayawada - 520007 (A.P), India. \\ *E-mail addreess: fakruddinspnl@gmail.com
}

\begin{abstract}
Ultrasonic velocity is measured experimentally at $3 \mathrm{MHz}$ frequency in the binary liquid mixture containing aniline and anisole at different temperatures over the entire composition range and theoretical values of ultrasonic velocity have been evaluated by using Nomoto's relation, Impedance relation, Van Dael ideal mixture relation. These theoretical values are compared with the experimental values. A good agreement has been found between experimental and theoretical ultrasonic velocities.
\end{abstract}

Keywords: Ultrasonic velocity; Aniline; Anisole; Binary liquid mixture

\section{INTRODUCTION}

In assessing the nature of molecular interactions and investigating the physicochemical behaviour of liquid and liquid mixtures ultrasonic study has been gained much importance for the past several years.

Many researcheres [1-9] carried out ultrasonic velocity and their investigations in liquid mixtures. The experimental results of ultrasonic velocity and theoretical results of ultrasonic velocities using Nomoto [10], impedence [11], Van dael [12] relations are interpreted in terms of molecular interactions.

In the present study ultrasonic velocities in the binary liquid mixture containing aniline and anisole are experimentally measured at different temperatures are compared with theoretical values [16].

\section{THEORETICAL}

The different theoretical ultrasonic velocicy relations used in the present study are expressed as follows, 
Nomoto's relation

$$
\mathrm{U}_{\mathrm{N}}=\left[\left(\mathrm{x}_{1} \mathrm{R}_{1}+\mathrm{x}_{2} \mathrm{R}_{2}\right) /\left(\mathrm{x}_{1} \mathrm{~V}_{1}+\mathrm{x}_{2} \mathrm{~V}_{2}\right)\right]^{3}
$$

Impedance dependent relation

$$
\mathrm{U}_{\mathrm{Im}}=\Sigma \mathrm{x}_{\mathrm{i}} \mathrm{Z}_{\mathrm{i}} / \Sigma \mathrm{x}_{\mathrm{i}} \rho_{\mathrm{i}}
$$

Van Dael ideal mixing relation

$$
\mathrm{U}_{\mathrm{imx}}=\left[\left(\mathrm{x}_{1} / \mathrm{M}_{1} \mathrm{U}_{1}^{2}+\mathrm{x}_{2} / \mathrm{M}_{2} \mathrm{U}_{2}^{2}\right)\left(\mathrm{x}_{1} \mathrm{M}_{1}+\mathrm{x}_{2} \mathrm{M}_{2}\right)\right]^{-1 / 2}
$$

\section{EXPERIMENTAL}

The chemicals used in the present study were purified by standard procedure [13]. The purity of samples was checked by comparing experimental values of density and ultrasonic velocity with the available literature [14-15] compiled in Table 1. Job's method of continuous variation was used to prepare the mixtures of required proportions.

The prepared mixtures were preserved in well-Stoppard conical flasks. After mixing the liquids thoroughly, the flasks were left undisturbed to allow them to attain thermal equilibrium.

The ultrasonic velocities were measured by using single crystal ultrasonic pulse echo interferometer (Mittal enterprises, India; Model: F-80X). It consists of a high frequency generator and a measuring cell. The measurements of ultrasonic velocities were made at a fixed frequency of $3 \mathrm{MHz}$. The ultrasonic velocity has an accuracy of $\pm 0.5 \mathrm{~ms}^{-1}$. The temperature was controlled by circulating water around the liquid cell from thermostatically controlled constant temperature water bath.

The densities of pure liquids and liquid mixtures were measured by using a specific gravity bottle with an accuracy of $\pm 0.5 \%$. Weights were measured with an electronic balance (Shimadzu AUY220, Japan) capable of measuring up to 0.1mg. An average of 4-5 measurements was taken for each sample.

Table 1. Experimental and literature values of density and ultrasonic velocity of pure liquids at $303.15 \mathrm{~K}$.

\begin{tabular}{|c|c|c|c|c|}
\hline \multirow{2}{*}{ Liquids } & \multicolumn{2}{|c|}{ U/ (m.s $\left.{ }^{-1}\right)$} & \multicolumn{2}{c|}{$\left.\rho / \mathbf{k g . m}^{-\mathbf{3}}\right)$} \\
\cline { 2 - 5 } & Expt. & Lit. & Expt. & Lit. \\
\hline Aniline & 1629 & $1614.5^{14}$ & 1.0160 & $1.0170^{14}$ \\
\hline Anisole & 1398 & ----- & 0.9849 & $0.9843^{15}$ \\
\hline
\end{tabular}

Expt. - Experimental; $\quad$ Lit. - Literature; 
Table 2. Experimental and theoretical values of velocities $\left(\mathrm{m} \cdot \mathrm{s}^{-1}\right)$ in binary liquid system aniline and anisole system at different temperatures.

\begin{tabular}{|c|c|c|c|c|}
\hline $\mathbf{X}$ & $\mathbf{U}_{\exp }$ & $\mathbf{U}_{\mathbf{N}}$ & $\mathbf{U}_{\text {Im }}$ & $\mathbf{U}_{\text {imx }}$ \\
\hline \multicolumn{5}{|c|}{$303.15 \mathrm{~K}$} \\
\hline 0.0000 & 1629 & 1629.0000 & 1629.000 & 1491.865 \\
\hline 0.0853 & 1605 & 1604.7181 & 1609.849 & 1455.214 \\
\hline 0.1733 & 1584 & 1580.7396 & 1589.986 & 1419.418 \\
\hline 0.2644 & 1569 & 1556.9924 & 1569.310 & 1384.333 \\
\hline 0.3587 & 1539 & 1533.4918 & 1547.785 & 1349.953 \\
\hline 0.4559 & 1524 & 1510.3462 & 1525.466 & 1316.403 \\
\hline 0.5571 & 1506 & 1487.3357 & 1502.085 & 1283.339 \\
\hline 0.6619 & 1482 & 1464.5997 & 1477.716 & 1250.935 \\
\hline 0.7707 & 1458 & 1442.0942 & 1452.248 & 1219.106 \\
\hline 0.8829 & 1434 & 1419.9786 & 1425.801 & 1188.052 \\
\hline 1.0000 & 1398 & 1398.0000 & 1398.000 & 1157.395 \\
\hline \multicolumn{5}{|c|}{$308.15 \mathrm{~K}$} \\
\hline 0.0000 & 1611 & 1611.0000 & 1611.000 & 1475.381 \\
\hline 0.0853 & 1584 & 1586.4735 & 1591.519 & 1438.451 \\
\hline 0.1733 & 1569 & 1562.2369 & 1571.331 & 1402.427 \\
\hline 0.2644 & 1551 & 1538.2180 & 1550.332 & 1367.162 \\
\hline 0.3587 & 1527 & 1514.4327 & 1528.489 & 1332.645 \\
\hline 0.4559 & 1509 & 1490.9915 & 1505.859 & 1298.999 \\
\hline 0.5571 & 1494 & 1467.6723 & 1482.175 & 1265.874 \\
\hline 0.6619 & 1458 & 1444.6168 & 1457.512 & 1233.446 \\
\hline 0.7707 & 1440 & 1421.7811 & 1431.763 & 1201.623 \\
\hline 0.8829 & 1404 & 1399.3275 & 1405.051 & 1170.603 \\
\hline 1.0000 & 1377 & 1377.0000 & 1377.000 & 1140.009 \\
\hline \multicolumn{5}{|c|}{$313.15 \mathrm{~K}$} \\
\hline 0.0000 & 1602 & 1602.0000 & 1602.000 & 1467.138 \\
\hline 0.0853 & 1569 & 1576.7373 & 1582.075 & 1429.503 \\
\hline 0.1733 & 1554 & 1551.7973 & 1561.416 & 1392.853 \\
\hline 0.2644 & 1533 & 1527.1054 & 1539.916 & 1357.034 \\
\hline 0.3587 & 1506 & 1502.6774 & 1517.539 & 1322.028 \\
\hline 0.4559 & 1491 & 1478.6259 & 1494.343 & 1287.956 \\
\hline 0.5571 & 1479 & 1454.7226 & 1470.051 & 1254.460 \\
\hline 0.6619 & 1440 & 1431.1123 & 1444.741 & 1221.711 \\
\hline 0.7707 & 1422 & 1407.7495 & 1418.297 & 1189.616 \\
\hline 0.8829 & 1392 & 1384.7995 & 1390.847 & 1158.371 \\
\hline 1.0000 & 1362 & 1362.0000 & 1362.000 & 1127.591 \\
\hline \multicolumn{5}{|c|}{ 318.15 K } \\
\hline 0.0000 & 1578 & 1578.0000 & 1578.000 & 1445.159 \\
\hline 0.0853 & 1554 & 1553.3336 & 1558.612 & 1408.389 \\
\hline 0.1733 & 1536 & 1528.9907 & 1538.502 & 1372.561 \\
\hline 0.2644 & 1515 & 1504.8979 & 1517.565 & 1337.526 \\
\hline 0.3587 & 1491 & 1481.0704 & 1495.766 & 1303.269 \\
\hline 0.4559 & 1476 & 1457.6179 & 1473.161 & 1269.909 \\
\hline 0.5571 & 1461 & 1434.3171 & 1449.476 & 1237.098 \\
\hline 0.6619 & 1425 & 1411.3091 & 1424.787 & 1205.004 \\
\hline 0.7707 & 1404 & 1388.5492 & 1398.981 & 1173.538 \\
\hline 0.8829 & 1374 & 1366.1981 & 1372.179 & 1142.891 \\
\hline 1.0000 & 1344 & 1344.0000 & 1344.000 & 1112.689 \\
\hline \multicolumn{5}{|c|}{$323.15 \mathrm{~K}$} \\
\hline 0.0000 & 1557 & 1557.9000 & 1557.900 & 1426.751 \\
\hline 0.0853 & 1536 & 1532.6929 & 1538.263 & 1389.583 \\
\hline 0.1733 & 1509 & 1507.8459 & 1517.880 & 1353.428 \\
\hline 0.2644 & 1491 & 1483.2832 & 1496.644 & 1318.128 \\
\hline 0.3587 & 1470 & 1459.0198 & 1474.517 & 1283.664 \\
\hline 0.4559 & 1458 & 1435.1659 & 1451.553 & 1250.152 \\
\hline 0.5571 & 1440 & 1411.4939 & 1427.474 & 1217.236 \\
\hline 0.6619 & 1407 & 1388.1465 & 1402.354 & 1185.082 \\
\hline 0.7707 & 1383 & 1365.0774 & 1376.072 & 1153.596 \\
\hline 0.8829 & 1356 & 1342.4485 & 1348.752 & 1122.968 \\
\hline 1.0000 & 1320 & 1320.0000 & 1320.000 & 1092.820 \\
\hline
\end{tabular}




\section{RESULTS AND DISCUSSION}

The theoretical evaluation of sound velocity based on different models in liquid mixture has been used to correlate with the experimental findings. The theoretical values of ultrasonic velocities calculated by using the equations (1-3) along with the experimental values for the liquid mixture at different temperatures of $(303.15,308.15,313.15,318.15$ and 323.15$) \mathrm{K}$ are given in Tables 2. From Table 2 it is observed that the theoretical values of ultrasonic velocity calculated by using various theories show deviation from experimental values.

The limitations and approximation incorporated in these theories are responsible for the deviations of theoretical values from experimental values. In Nomoto's theory, it is supposed that the volume does not change on mixing. But on mixing two liquids, the interaction between the molecules of the two liquids takes place because of the presence of various types of forces such as hydrogen bonding, dipole-dipole, dispersive forces, charge transfer and dipole-induced dipole interactions.

The deviations of experimental values from theoretical values calculated using Van Dael Ideal mixture relation might be due to the compressibility of the component liquids in the present mixtures. The deviations of experimental values and values calculated from impedance relation imply non-additivity of acoustic impedance in the liquid mixtures. Thus, the observed deviation of theoretical values of velocity from the experimental values shows that weak molecular interactions are taking place between the component molecules.

\section{CONCLUSION}

Ultrasonic velocities in the binary liquid mixture containing aniline and anisole at different temperatures are determined, and the validity of different theories is checked. Over all the observations it is cleared that in all the theories Nomoto's relation gives best results followed by Impedance theory.

\section{References}

[1] Kannappan V., Xavier Jesu Raja S., Jaya Santhi R., Indian J. Pure Appl. Phys. 41 (2003) 690.

[2] Pandharinath S., Patil V. U., Hassan Mehdi, J. Indian Chem. Soc. 78 (2001) 368.

[3] Ali Anwar, Nain Anil Kumar, Sharma Vinod Kumar, Ahmad Shaki, Acoust. Lett. 24 (2001) 9 .

[4] Kannappan V., Jaya Santhi R., Xavier Jesu Raj S., Phys. Chem. Liq. 14 (2003) 133.

[5] Kannappan V., Jaya Santhi R., Malar E. J. P., Phys. Chem. Liq. 40 (2002) 507.

[6] Kannappan V., Jaya Santhi R., J. Acoust. Soc. Ind. 29 (2001) 192.

[7] Deepali P., Gulwade Narwade M. L., Wadadkar K. N., Indian J. Chem. 43A (2004) 2102.

[8] Chauhan S., Syal V. K., Chauhan M. S., Indian J. Pure Appl. Phys. 32 (1993) 816.

[9] Narendra K., Narayanamurthy P., Srinivasu Ch., Pak. J. Sci. Ind. Res. 55 (2012) 59-67. 
[10] Nomoto O., J. Phys. Soc. Jpn. 13 (1958) 1528-1532.

[11] Baluja S., Parsania P. H., Asian J. Chem. 7 (1995) 417-423.

[12] Subhash Bhatia C., Rachana Bhatia, Gyan Dubey, J. Mol. Liq. 152 (2010) 39-52.

[13] Perrin D. D., Armarego W. L. F., Purification of Lab. Chem., 3rd ed., Pergamon Press, Oxford 1980.

[14] Vasantharani P., Balu L., Ezhil Pavani R., Shailajha S., Global Journal of Molecular Siences. (2009) 42- 48.

[15] Wen- Lu-Weng, J. Chem Eng. Data. 44 (1994) 788-791.

[16] M. Durga Bhavani, A. Ratnakar, Ch. Kavith, International Letters of Chemistry, Physics and Astronomy 5 (2013) 1-6. 